\title{
El problema de la educación en la Staatslehre de 1813
}

\author{
The problem of education in Fichte's Staatslehre from 1813
}

\author{
Carlos Aurélio Morujão \\ cmorujao@fch.lisboa.ucp.pt \\ (Universidade Católica Portuguesa, Lisboa, Portugal)
}

Resumen: Este artículo aborda la teoría de la educación en la Staatslehre de Fichte de 1813. Intento mostrar que esta teoría está estrechamente relacionada con la idea de Fichte de las relaciones entre ética y política y con su idea del carácter transitorio del Estado. De hecho, Fichte piensa que, en un mundo futuro estructurado de acuerdo con principios éticos, el poder estatal será superfluo. Pero esto implica un esfuerzo por educar a las personas que solo podrá lograr alguien investido tanto con la sabiduría suprema del orden divino del mundo como con el poder de la coerción. Este será el papel asignado al "señor de la coacción" (Zwingherr). Este, al no tener lugar en una exposición puramente a priori de la filosofía del Estado, como fue el caso de la Rechtslehre de 1812, debería tener lugar en una exposición atenta a las circunstancias particulares en las que se expone la doctrina, como es el caso con la Staatslehre de 1813. Al final examino algunas interpretaciones erróneas (según mi punto de vista) de la filosofía de la educación de Fichte y enfatizo, contra Marc Maesschalk, el hecho de que el proyecto de Fichte difiere de la idea de Husserl de una comunidad de sujetos trascendentales autónomos y responsables. Para Fichte, es necesario alguien que diga hasta qué punto los individuos aún no son libres y tienen que ser coaccionados con vistas a la libertad.

Palabras clave: Fichte; educación; coerción; ética y política.
Abstract: This paper addresses the doctrine of education in Fichte's Staatslehre from 1813. I try to show that this theory is closely connected with Fichte's idea of the relations between ethics and politics and with his idea of the transient character of the state. In fact, Fichte thinks that in a future world structured according to ethical principles, state power will be superfluous. But this implies an effort to educate people that only someone invested both with the supreme wisdom of the divine world order and the power of constraint will be able to carry through. If a reference to the role of the Zwingherr finds no place in Fichte's 1813 a priori exposition of the philosophy of state, it has its due place in the 1812 exposition that takes into account the actual historical circumstances in which the doctrine is exposed. At the end, I examine some misinterpretations (according to my point of view) of Fichte's philosophy of education and I stress, against Marc Maesschalk, the fact that the Fichtean project differs from Husserl's idea of a community of autonomous and responsible transcendental subjects. For Fichte, the Zwingherr is someone who knows how far men are from being free and the extent to which they must be constrained in order to be so.

Keywords: Fichte; education; coercion; ethics and politics.

Heinrich Heine escribió una crítica muy dura de las filosofías del idealismo alemán y de sus consecuencias políticas. Quizás Heine fue un poco injusto con Kant, pero lo que dice de Fichte y de la filosofía de la naturaleza me parece, en lo 
fundamental, correcto. Heine, un seguidor del socialismo utópico de Saint-Simon, hablaba a los franceses y escribió su crítica en la Revue des deux Mondes. La redactó cuando se avecinaba en Europa una nueva época de revoluciones, la de 1848, comparando la pasada revolución en Francia con la futura revolución alemana y europea, que resultaría de la filosofía del idealismo. Esto fue lo que escribió:

la revolución alemana no será benévola ni más dulce, porque la crítica de Kant, el idealismo trascendental de Fichte y la filosofía de la naturaleza la habrían precedido. Estas doctrinas han desarrollado fuerzas revolucionarias que nada más que están esperando el momento para hacer explosión y llenar el mundo de espanto y de admiración. Entonces aparecerán kantianos que ya no querrán escuchar hablar de piedad en el mundo de los hechos ni en el de las ideas, y trastornarán sin misericordia, con el hacha y la espada, el suelo de nuestra vida europea para extirpar de ella las últimas raíces del pasado. Vendrán sobre la misma escena fichteanos armados, cuyo fanatismo de la voluntad no podrá ser reprimido ni por el temor ni por el interés (...). Pero los más espantosos de todos serán los filósofos de la naturaleza, que intervendrán por la acción en una revolución alemana y que se identificarán ellos mismos con la labor de destrucción; pues si la mano del kantiano golpea fuerte y con golpe firme y a tiro hecho, porque su corazón no está conmovido por ningún respeto tradicional; si el fichteano menosprecia atrevidamente todos los peligros, porque para él no existen para nada en la realidad; el filósofo de la naturaleza será terrible en tanto que se pone en comunicación con los poderes originales de la naturaleza, en tanto que conjura las fuerzas escondidas de la tradición y puede evocar las de todo el panteísmo germánico. Entonces se despierta en él este ardor del combate que encontramos en los antiguos alemanes y que quiere combatir, no por destruir, ni incluso por vencer, sino únicamente por combatir (Heine, 1834, pp.675-678).

Heine no menciona a ningún filósofo de la naturaleza, alguno de aquellos que va más lejos que los kantianos impiedosos y los «fichteanos armados». Tal vez mentaba a las filosofías de Schelling y de Hegel y su pretensión de conocer los poderes últimos de lo real. La filosofía de Fichte, incluso la filosofía de la imagen del último Fichte, en parte dirigida contra Schelling, no tiene tal objetivo. Para Fichte, tales poderes serían las leyes muertas de una naturaleza independiente de la libertad humana. Pero la naturaleza no es más que el campo de acción de una fuerza libre, movida por un concepto. La naturaleza proporciona la masa - que no es más que el espíritu en su forma visible - y el espíritu el principio del movimiento, decía Fichte al comienzo de la tercera parte de la «Tercera Sección» de la Staatslehre (Fichte, 1845, p.461). Al ejercitar esa fuerza, añadía Fichte, si paras y te imaginas siendo, ya caíste en la Nada. El voluntarismo que Heine atribuye a Fichte corresponde perfectamente a la posición de éste cuando afirmaba antes, en su «Introducción General» (ídem, p.388), que es la voluntad que hace comenzar absolutamente el ser y que el mundo es apto para recibir los resultados de la acción de una voluntad libre; y si por casualidad no lo fuera, sería obligación de la voluntad prepararlo para tal.

La Staatslehre de 1813 es casi un testamento político. El texto original de estas Lecciones no nos llegó, sino solo la versión publicada por Immanuel Hermann 
Fichte, cuyo origen se desconoce. El hecho de que estas son Lecciones (cuyas fases de preparación se pueden seguir usando el Diario de Fichte) explica el carácter oral del estilo, pero también algunas digresiones. De hecho, a Fichte también le preocupaba la determinación de la naturaleza de la guerra (un problema que ya lo había ocupado en sus escritos sobre Maquiavelo) y la relación entre su teoría de la imagen, tal como la había estado desarrollando desde 1805, y la filosofía moral.

El ámbito de las Lecciones de 1813 es la filosofía práctica, pero su objetivo específico es la educación. Se trata de educar para las tareas que la ciudadanía impone en el presente - es decir, en un momento determinado de la serie de los acontecimientos humanos que constituyen la historia - con vistas a la obtención de estados futuros de esa misma serie; el que tiene que ser educado todavía no alcanza a verlos, pero el filósofo los conoce, pues está en posesión de la razón que hace progresar a la serie (Fichte, 1845, p.394). A este problema dedicaré la primera parte de mi ponencia. Pero la teoría de la educación de la filosofía del último Fichte solo es comprensible si entendemos que es solidaria con una teoría de una escisión o desdoblamiento del Yo. Gracias a eso, el Yo, mientras va siendo educado, puede ver las etapas o niveles de su propio proceso educativo, es decir, lo que ya ha alcanzado y lo que aún le falta. A este nuevo problema, al que denominaré el problema del punto de apoyo en el Yo de la acción educativa del educador (que Fichte llamó, como es sabido, der Zwingherr), dedicaré la segunda parte de mi ponencia. En esta segunda parte reaccionaré a la lectura que Marc Maesschalck hace de la Staatslehre y a su interpretación de la misión educativa del Zwingherr como formación de una «comunidad de atención» (Maesschalck, 2006, p.44) a los principios que deben regir la vida comunitaria, a fin de que sea la imagen de la vida divina. Tengo algunas dudas acerca de la posibilidad de constituir una comunidad de atención en el sentido de Maesschalk e intentaré mostrar que, aunque si por un absurdo ella fuese posible, no sería deseable que sobre ella se fundase la vida social.

\section{La educación}

Un comentarista, Claude Piché (2003, p.171), defiende que el propósito de Fichte con su doctrina de la educación es el de acelerar el ritmo de la historia, de modo que ésta alcance su finalidad, que es la constitución de una comunidad ética perfecta. Hablando del legislador supremo, en la Tercera Parte de la Staatslehre, dice Fichte que su misión es la de insuflar la vida en un cuerpo político exangüe, hacerlo resurgir del reino de los muertos (Fichte, 1845, p.458). Esta finalidad dirige su proyecto educativo. Por esta razón, la educación no es un accesorio de la Doctrina de la Ciencia, ni es sólo una aplicación de ella a un dominio particular de la vida. La educación, si entendí bien el proyecto político y educativo fichteano, es la propia 
Doctrina de la Ciencia, en tanto que filosofía práctica, tal como ella tiene que ser enseñada y vivida en un momento histórico particular, que es la época de Fichte. El proyecto educativo tiene una profunda relación con el nivel de la época, que se caracteriza por el abandono del instinto racional (Vernunftinstinkt) en la totalidad de la vida comunitaria. Además, quien entendió la Doctrina de la Ciencia sabe que la filosofía es creadora de un ser a partir de un concepto de fin.

Hay en Fichte una doble vertiente en el problema de la educación: se trata de saber cómo debe el estado educar a los ciudadanos, pero también cómo la universidad debe educar ya sea a aquellos que se destinan a ejercer futuras funciones en la administración y en el estado ya sean a los miembros de las clases trabajadoras. Una cosa, sin embargo, unifica las dos preocupaciones: se trata de formar ciudadanos libres, en el sentido en que libertad significa, no tanto la ausencia de constreñimiento, o incluso una auto-limitación recíproca de las libertades individuales, sino la imposición a sí mismo, gracias a la educación, de normas que permitan el desarrollo en común de la libertad. Normas que, además, deben ser comprendidas por todos, pero que no todos, en su situación presente, logran comprender. Pues para Fichte ser libre no es sólo no ser constreñido, sino también actuar de acuerdo con una comprensión propia de las leyes de la libertad (Fichte, 1845, p.439). Por lo tanto, existe un estado mental apropiado que la presentación oral de la Staatslehre debería plantear en sus oyentes (ídem, p.394). Como veremos a lo largo de esta comunicación, aquí hay muchos problemas.

La educación tenía en Kant un papel mediador. Por medio de ella se da el paso de la política a la moral, permitiendo que la razón -objetivamente práctica, aunque actuando sólo legalmente - se torne subjetivamente práctica. Asimismo - añadirá Kant -, la educación y el derecho tienen en común el hecho de que no podemos pensarlos sin coacción: la educación empieza con la inculcación de la idea de que hay que ser educado y que hay que asumir las disposiciones necesarias para ello (por ejemplo, la atención a lo que dicen los maestros); el derecho estipula las formas que permiten el acuerdo entre las libertades y las sanciones para quienes no las respetan. Si bien para Kant hay una diferencia entre política y moralidad, tal diferencia no existe para Fichte. La consecuencia de eso para la educación es clara: la legislación política tiene un alcance moral inmediato - «La ley jurídica es ella misma una ley moral» (Fichte, 1845, p.432) -, la adecuación de los comportamientos a la forma de la ley tendrá reflejos en sus contenidos y el estado se encargará de la educación del ciudadano para que ello sea posible. Esa educación se hace en las instituciones de enseñanza secundaria y en las universidades. El éxito de esta educación es la principal garantía de la instauración de un orden político-moral.

Sin embargo, hay para Fichte un conjunto de problemas previos. ¿Cómo llegamos al conocimiento de la ley que al mismo tiempo es moral y jurídica? ¿Qué tipo 
de ley es esa? ¿Cómo garantizamos que nuestras leyes particulares sean deducibles de la ley suprema, siendo por ello moral y jurídicamente válidas? Además, ¿cómo es posible garantizar que sean estas leyes particulares las que el Zwingherr debe intuir y no otras leyes diferentes? ${ }^{1}$

Fichte comienza la Staatslehre con un breve recorrido de sus tesis metafísicas fundamentales, insistiendo en la distinción entre un conocimiento de cosas y un conocimiento de las leyes que rigen las cosas. Al primer tipo de conocimiento Fichte lo llamará «imagen de las cosas» (una cosa sin su imagen sería desconocida por nosotros y una imagen que no remite a aquello de lo cual es imagen no sería conocimiento), mientras que el segundo tipo de conocimiento, el de las leyes, lo llamará imagen de la imagen.

Fichte ve el orden ético-político del estado como una forma de vida donde se refleja la vida que lo crea todo. Una comunidad de sujetos libres configura la naturaleza y la sociedad de acuerdo con la imagen de lo que es para ella una vida deseable. Asimismo, aquella imagen no puede ser la imagen de un ser preexistente, sino más bien un concepto de finalidad, o sea, una imagen que quiere obtener el ser gracias a la eficacia de la libertad (Fichte, 1845, p.386). Ese ser es en realidad una vida y su visibilidad está garantizada por la libertad actuando en el mundo sensible. Las leyes de los estados deben ser una imagen de esa vida a la que podemos llamar divina. Sin embargo, según Fichte, no lo son porque se trate del ser de Dios puesto una segunda vez, sino en tanto que son la expresión del devenir (ídem, p.387) de una comunidad de libertades.

La educación es, para Fichte, ante todo, el modo de hacer que cada uno interiorice aquella imagen, o mejor, que cada uno la produzca en sí mismo desarrollando el órgano que permite su captación. Desde un punto de vista práctico, eso significa: educarse para contrariar la irrupción, en sí mismo, de una voluntad opuesta al derecho (Fichte, 1845, p.435). Solo una educación que haga efectiva esta interiorización justifica el papel de las instituciones de enseñanza, pues son estas las que se encargan de proporcionar al Estado ciudadanos que harán inútil un día la coerción que hoy necesariamente se ejerce sobre ellos.

\footnotetext{
1 Me gustaría llamar la atención sobre un hecho que justificará, más adelante, la comparación que establezco entre el Zwingherr de Fichte y el phronimos del que habla Aristóteles. Este último no actúa de acuerdo con leyes (no podría hacerlo, ya que su acción se ejerce en un campo en el que no existen), mientras que el primero sí. Pero, por otro lado, las leyes que sigue el Zwingherr no son producto de su voluntad legislativa. Actuar de acuerdo con las leyes que tienen su origen en la voluntad, o actuar sin leyes, no parece, para Fichte, ser algo sustancialmente diferente. Quien lo haga merece solo el nombre de déspota. Si el Zwingherr, como escribió Heinrich Heine, «golpea fuerte y con un golpe firme» (o, al menos, nada le impide hacerlo), sin embargo, no lo hace arbitrariamente. Como veremos más adelante, su acción es principalmente de carácter educativo.
} 


\section{Estado y coerción}

Ya vimos que ser libre no es solamente no ser coaccionado; ser libre es, además, tener en sí mismo el principio de su coacción. La ausencia de coacción significa que ya soy libre y no un Naturwesen. Además, en la medida en que soy un Naturwesen, pero en transición hacia la libertad, tengo ya el principio de mi ser en el reino de la libertad (Fichte, 1845, p.435). Esto significa que sólo puedo ser coaccionado en la medida en que esa coacción me encamina hacia la libertad. Es a ese tipo de coacción que Fichte va a llamar educación. Es decir, el estado, aun practicando la coerción, parece que no se define por el poder de coaccionar. La Rechtslehre de 1812 iba aún más lejos en este camino. Ahí Fichte defendía que, una vez realizada su tarea educativa, el estado se suprimiría a sí mismo, dando lugar a una relación puramente moral entre individuos libres. Esta idea, retomada años más tarde, en términos casi idénticos, por Marx y Engels, no es enteramente original; Schelling la había defendido un poco antes, en 1810, en sus Stuttgarter Privatvorlesungen.

Es posible formular este problema mediante dos proposiciones antitéticas. La tesis nos dice: el principio de la libertad individual es inviolable. Cada uno debe actuar de acuerdo con la intelección que le es propia (Fichte, 1845, p.439). La antítesis, sin embargo, contrapone: el uso de esta libertad puede derivarse de una ley de la naturaleza e impedir la libertad de todos, es decir, la coexistencia de las libertades. Del principio de libertad individual se desprende la necesidad de una abstención de actos que impidan la coexistencia de las libertades. Sin embargo, existe en los individuos una voluntad, que hay que superar, contraria al derecho (ein rechtswidrige Willen) (ídem, p.435) Esta voluntad es un poder de la naturaleza que solo puede ser contrariado por un poder de la naturaleza de sentido opuesto. Es decir, por medio de la represión. Fichte dice:

Se trata, en primer lugar, de la libertad de un ser natural, por consiguiente, de la voluntad natural. Esta no tiene absolutamente ningún derecho de manifestarse exteriormente; ella debe ser reprimida dondequiera que se muestre y quien la reconozca tiene el derecho de reprimirla, si lo puede hacer. El derecho exterior debe imponerse por constreñimiento; interiormente, sin embargo, la libertad debe ser formada para la intelección por medio de la instrucción (ídem, p.436).

Es importante tener en cuenta lo siguiente: el Zwingherr no puede extirpar la mala voluntad interior; solo puede impedir acciones contrarias a las leyes, usando un poder de la naturaleza y contando con el miedo a las penas. La necesidad del constreñimiento parte sólo de la constatación de que la abstención de acciones contrarias al derecho tiene que ser producida mientras que la libertad siga siendo una libertad natural. La síntesis entre las dos proposiciones antitéticas antes referidas 
concluye que esto sólo vale mientras dure el proceso educativo, cuya finalidad es llevar a cada individuo a comprender la necesidad de abstenerse de ciertas acciones.

\section{¿Vernunftinstinkt o Einsicht?}

La coacción se legitima por su finalidad. Refiriéndose a ésta, Fichte afirma: «La buena voluntad del derecho debe ser construida en cada uno sobre la base de una intelección propia» (Fichte, 1845, p. 436). Este es el papel desempeñado por la educación. En otras palabras, hay que formar la Einsicht, o sea, la intelección de cada individuo, a sabiendas que todo lo que la educación podrá alcanzar es solamente provocar en cada uno la necesidad de tener esa intelección. Cuanto más honda sea nuestra intelección, cuanto mejor sea nuestra voluntad, tanto menor será la coacción (ídem, p. 439). Pero hay que determinar mejor los fines específicos de la educación. En 1798, en la Nova Methodo, Fichte hablaba de la necesidad de restaurar el Vernunftinstinkt por medio de la educación (Fichte, 1994, p.6), un instinto natural que todos los hombres poseen. El problema es que la época había pervertido el Vernunftinstinkt.

Vernunftinstinkt y Einsicht no son exactamente lo mismo. En la Nova Methodo, el Vernunftinstinkt se distingue de la ciencia como el saber actuar se distingue de la ciencia de la acción, y la tranquilidad de espíritu que resulta de una acción conforme a la ley no es todavía el conocimiento de la propia ley. Parece haber la posibilidad de un paso del Vernunftinstinkt a la ciencia, la cual es motivada por un impulso cognitivo que, si bien está presente en todos los hombres, no en todos encuentra las condiciones para ser llevado hasta el final. El Vernunftinstinkt de Fichte me recuerda a lo que el filósofo español Ortega y Gasset llamaba el «fondo insobornable» existente en cada ser humano, esto es, la posibilidad de orientar el pensamiento hacia la verdad, pero también la disposición moral para perseverar en ese esfuerzo. Sobre este aspecto, Reinhard Lauth ha llamado la atención acerca de la posibilidad de establecer un paralelo con Rousseau (Lauth, 1984, p.384). Para el autor francés, la cuestión decisiva consistía en si la humanidad poseía todavía la virtud suficiente para realizar el contrato social.

Desde el punto de vista de la forma, el Zwingherr sólo tiene derecho a coaccionar en la medida en que demuestra que su Einsicht sobre la esencia del derecho es el correcto. Los demás tienen el deber de seguir sus disposiciones en la medida en que la Einsicht de ellos no es todavía la correcta (Fichte, 1845, p.437). El Zwingherr no actúa en su propio nombre; él encarna la comunidad moral que está en proceso de realización. Fichte escribe: «La coerción (...) es el medio por el cual la intelección de la comunidad se une al individuo y el individuo se transforma en un ser espiritual a partir de un mero ser natural». Fichte sostiene, desde luego, que es 
natural que los hombres no quieran reconocer otras leyes sino aquellas que se han dado a sí mismos; sin embargo, añade que esta afirmación no debe entenderse desde un punto de vista psicológico. Es decir, nadie puede reclamar la libertad de no ser constreñido, o al menos una disminución de las restricciones que penden sobre sí mismo, si no está empeñado en el proceso de desarrollo de su Einsicht. Como afirma Fichte: «mehr Einsicht und guter Wille, weniger Zwang.» ("más intelección y buena voluntad, menos coerción") (ídem, p.439).

En Fichte no existe el problema de la limitación del poder del educador, ya que se admite la hipótesis de que el soberano esté completamente sometido al derecho, esto es, que identifique su voluntad con lo que la idea de derecho prescribe. El derecho, a su vez, sería la condición de posibilidad de la libertad de los individuos. Para estos, por tanto, la sumisión completa a las leyes coincide con la completa libertad. Si bien Fichte percibe la posibilidad de que cualquiera haga de su voluntad un absoluto - es lo que, en su opinión, sucedió con Napoleón (Lauth, 1994, p.405) - no se percibe en cambio por qué no podría pasar lo mismo con el Zwingherr. Sin embargo, Fichte admite que la sumisión total coincide con la libertad total, siempre que sea una sumisión al derecho (Renaud \& Savidan, 2001, p.187).

Fichte no se plantea el problema de los límites de la soberanía, algo muy importante para la tradición de la filosofía política heredera de John Locke. La tesis de un «gobierno limitado» es incompatible con la idea de que el gobierno tiene una misión educativa específica; la tesis del gobierno limitado supone que el proceso de legitimación de su autoridad radica en un contrato originario entre individuos libres, los cuales aceptan limitar su libertad en nombre de un mayor bien de todos. Tal libertad, sin embargo, no existe para Fichte; pues la libertad, para él, tiene su origen en el pacto que instaura la sociedad y el derecho. Fichte sólo tiene desprecio por esta concepción, opuesta a la suya, que describe en estos términos:

Proteger esos medios de vida a los que se da el nombre de propiedad, independientemente de cómo se hayan adquirido, protegerlos contra el robo violento de todo tipo, es de lo que el Estado trata; el Estado es sólo el medio para este propósito y ocupa así el tercer lugar en esta serie: primero la vida, después los bienes, por fin el Estado que los protege (Fichte, 1845, p.403).

Hay que formar en los individuos una nueva intelección que sea capaz de poner su voluntad en movimiento y de despertar en ellos una nueva concepción de la vida y, sobre todo, de su propia vida individual. En la Staatslehre escribió: «Ninguna coerción que no esté en relación con la educación de la intelección con vistas al derecho» (Fichte, 1845, p.437). El Zwingherr ya tiene tal intelección. Fichte añade que él tiene por supuesto que demostrarlo, y que los demás hombres tienen razón al pedirle tales pruebas (ídem, íbidem). Sin embargo, no queda claro cuáles puedan ser estas. Parece que Fichte considera que sea suficiente que los hombres sigan 
las directivas del Zwingherr y que el hecho de que las siguen les permitirá, algún día, reconocer su validez (ídem, p.445). Creo que, hasta cierto punto, la definición fichteana del Zwingherr se asemeja a la definición del político según Carl Schmitt: para este último, el político es el que decide en un estado de excepción, aun cuando sea también el político quien decide qué estado es, de hecho, el de excepción, para que pueda justificar su intervención. Asimismo, en la línea continua (ídem, p.442) que representa la evolución de la idea de derecho, el Zwingherr decidirá en qué punto se encuentra su época y obligará a todos los hombres a actuar en función del objetivo final.

Las similitudes con el pensamiento político-jurídico de Schmitt (que leyó a Fichte cuidadosamente) no terminan aquí. El Zwingherr de Fichte se se torna necesario en un momento en que la distinción entre amigo y enemigo debe hacerse con la mayor claridad. Se podría argumentar que esta distinción es jurídicamente irrelevante y que los conceptos en los que se basa carecen de la claridad necesaria. Pero es precisamente esta falta de claridad la que maximiza su efecto retórico. Fichte no dejará de aprovecharlo para denunciar a Napoleón como el enemigo contra el cual todos los alemanes deben unirse. ${ }^{2}$ Una vez que se hace la distinción entre amigo y enemigo, el estado de guerra se sigue necesariamente. No necesariamente (y Schmitt no dejará de llamar la atención sobre esto) una guerra entre estados, sino una guerra en la que el pueblo armado adquiere su propia identidad, convirtiéndola en un imperativo ético y repeliendo al invasor extranjero. En la genealogía de la guerra de guerrillas, Schmitt incluirá con simpatía el pensamiento de Fichte en 1813 (Bazzan, 2019, p.261).

No obstante, Fichte añade que el Zwingherr irá perdiendo su carácter propio y transformándose en mero educador. Tampoco es muy claro cómo se va a procesar esta trasformación, pero al menos para Fichte es claro que ella se va a realizar. Encontramos aquí - al menos a mí me lo parece - algo muy parecido a la doctrina de Marx de la progresiva desaparición del Estado. ${ }^{3}$ Esta coincidencia tal vez no sea fortuita, pero no es para mí el punto fundamental. Lo que me causa algún problema es que Fichte parece decir que la coerción se vuelve innecesaria cuando todos los que fueron constreñidos reconocen finalmente que fue necesario que haya habido coerción.

2 Existe una relación entre el pueblo y la lengua, es decir, entre ser alemán y hablar el idioma alemán, que Fichte no dejará de explorar y que culminará, en el siglo XX, en autores como Schmitt, una vez más, o Martin Heidegger. Pero aquí Fichte no es completamente innovador y no hará más que explorar algunas tendencias en la filosofía del lenguaje del romanticismo.

3 Cf. lo que dice Fichte al final de la Staatslehre (1845, p.599): "el estado actual de constricción morirá pacíficamente, sin estar sujeto a ninguna manifestación de fuerza, debido a su propia nulidad causada por el tiempo y será necesario que el último heredero de la soberanía, si todavía existe, se disuelva en la igualdad universal, yendo a la escuela del pueblo y viendo lo que ella puede hacer por él». 


\section{Libertad y propiedad}

El modo como el Zwingherr ejerce su acción educativa no se presenta, sin embargo, con la claridad de un proceso lógico. Por supuesto que hay cosas que son absolutamente claras, como, por ejemplo, el hecho de que la libertad de alguien no puede verse obstaculizada por la libertad de otra persona; o el hecho de que cada uno de ellos debe tener un ámbito en el que su acción libre sea posible. Pero las dos proposiciones anteriores no se dejan fácilmente compatibilizar. La propiedad es el ámbito de acción de cada uno en el mundo sensible. ¿Cuál debe ser la exacta dimensión de ese ámbito? Contestaremos que el estado debe garantizar a cada uno el mínimo de propiedad que haga posible su acción. Pero ¿cómo determinar exactamente lo que es el mínimo para cada uno?

Fichte evolucionó en relación con este asunto. Primero, en 1796 decía que cada uno es el señor absoluto de su propiedad y sólo debe contribuir al estado con lo mínimo necesario para que el estado asegure la supervivencia de los otros. Más tarde, en 1800 el derecho de propiedad es el derecho de cada uno de obtener de sus acciones lo que esperaba. Para ello, el estado debe realizar dentro de sus fronteras un reparto igualitario de los recursos e impedir la interferencia de los factores que no puede controlar, como por ejemplo el comercio exterior (Renaut \& Savidan, 2001, p.194). La teoría de la imagen va a imponer un tercer y último cambio en la reflexión de Fichte sobre la propiedad. John Locke defendió que el derecho de propiedad era una prolongación del derecho de cada uno a su propio cuerpo. Creo que Fichte sigue reaccionando, en 1813, contra esta tesis, pero de forma diferente a como lo había hecho anteriormente. En las dos primeras fases que he mencionado más arriba, pensaba que una teoría de la intersubjetividad, basada en la acción recíproca, superaba tanto el individualismo moral como una teoría social basada en la idea de contrato.

Antes que nada, solo la propiedad permite la libertad individual, es decir, que el individuo sea la primera causa independiente de sus acciones (Fichte, 1845, p.433). Sin embargo, se trata solamente de la acción libre en el mundo sensible (ídem, p.441) a la que cada uno tiene derecho, así como al reposo y al placer. Pero, en la Sección Segunda de la Staatslehre, Fichte había dicho tres cosas distintas: primero, que la propiedad es un medio para la conservación de la vida y la vida es lo que se encuentra en el nivel más alto; segundo, que la perspectiva consistente en hacer del estado el garante de la propiedad, transformando así el estado en un estado de propietarios, o a su servicio, es una manera de ver estrecha y unilateral (ídem, p.403); tercero, que es posible defender (aunque no es lo que Fichte sostiene) que si los propietarios se pudieran garantizar contra el robo entonces el estado se volvería inútil. Creo que el problema de Fichte, en lo esencial, se mantiene idéntico 
a lo largo de su vida: se trata de saber de qué forma una tendencia natural (la de auto-conservación) puede tener la forma de un comportamiento moral que funde la libertad de todos. Una nueva respuesta a este problema está en la base de la teoría de la educación en 1813. En el núcleo de esta teoría está la idea de que no se trata de mirar la vida social como un ser que sea una imagen de la vida absoluta, sino de hacer aparecer en la vida social una imagen de esa otra vida. Es este «hacer aparecer» que da al proyecto educativo fichteano su carácter propio.

\section{¿Cómo se justifica la acción del Zwingherr?}

Con el análisis de la forma en la que se procesa este «hacer aparecer» entro en la segunda parte de mi ponencia. A pesar de que Fichte dice que la acción del Zwingherr no puede producir efectos interiores - esto es, que no puede conducir a nadie a la moralidad -, el resultado esperado no es sólo el de una conformidad externa a lo que la ley obliga. La comunidad de los sujetos morales es superior a la comunidad jurídica y es sólo con vistas a la primera que la educación tiene sentido. Ahora bien, para que la finalidad de la educación pueda ser alcanzada es necesario que ella se apoye en la estructura de la conciencia del sujeto que debe ser educado.

Marc Maesschalck llama a este «hacer aparecer» la constitución de una «comunidad de atención» (communauté d'attention). Para explicarlo recurre a una comparación entre lo que dice Fichte sobre la atención en la WL de 1804 y lo que dice Husserl en Filosofía Primera. Esta relación establecida por Maesschalck entre Fichte y Husserl me suscita algunas dudas. La atención de la que habla Fichte, en la $5^{\text {a }}$ Lección de la WL de 1804 (Fichte, 1985, p.66), tiene que ver con la condición necesaria para la comprensión de la WL, que está siendo expuesta oralmente. No puede ser una atención flotante, más o menos intensa: una vez que el oyente se debe apropiar del pensamiento expuesto por Fichte, debe habituarse al lenguaje peculiar de la WL, debe reconocer el paso del saber factual, que ya posee, a la evidencia genética de lo que ya sabía. ( 0 que, en realidad, no sabía, ya que sin evidencia genética el saber factual carece de valor). Husserl exigía el mismo tipo de esfuerzo a sus lectores, al punto de decirle a Dorion Cairns que las Meditaciones Cartesianas deberían ser leídas como un libro de matemáticas, en el que la evidencia de cada argumento se funda en la evidencia de los anteriores y en la evidencia del proceso del paso de unos a otros.

Pero no creo que sea esto lo que está en cuestión en los textos de Filosofía Primera, correspondientes a la Lección $n^{\circ} 42$, los cuales cita Maesschalck. En esta Lección, Husserl, tomando como ejemplo los actos valorativos, procede a un análisis de los actos reflexivos, donde el Yo que reflexiona puede distanciarse de la valoración efectuada anteriormente por el yo que ahora es objeto de reflexión; con ello, el 
interés dominante del Yo se ve alterado y el acto primitivo, de naturaleza volitiva, se transforma en un acto judicativo. Así, en un acto valorativo no se pone (setzt) el valor, sino la cosa valorada, mientras que en la reflexión sobre el acto primitivo es el propio valor que es puesto (Husserl, 1959, pp.105 y 315).

Sin embargo, no es un mero azar el hecho de que Maeschalck acerque estos dos textos y defienda que ambos hablan de la misma actitud que, en la Staatslehre, el educador quiere despertar en el educando. Esta lectura está plenamente de acuerdo con su interpretación de este texto de Fichte respecto del papel que atribuye a la atención en la formación de una comunidad de sujetos libres y con la concepción de derecho y de política que subyace a tal interpretación. Por lo demás, ni siquiera creo que esté equivocada, pues, en cierto modo, concuerda con las intenciones de Fichte. Tengo dudas de que, por un lado, la empresa de Fichte pretenda estipular las condiciones para un acuerdo posible entre las libertades y, por el otro, aunque se quisiera, según lo que nos propone la Staatslehre, que tal acuerdo se obtenga de forma más satisfactoria que según los principios de la teoría de la intersubjetividad defendida, por ejemplo, en 1796.

Basta que este supremo entendimiento sea encontrado para que todo sea tomado en su primera claridad. Obedecer al entendimiento, en la medida en que hasta ahora está revelado en el mundo, es aquello a lo que todo el ser libre se encuentra obligado; porque se trata de la ley de la libertad y sólo en la medida en que cada uno la sigue es libre; eso es la demostración de su libertad y si no la sigue es un poder ciego de la naturaleza (Fichte, 1845, p.444).

Este es un pasaje muy importante pues Fichte plantea el problema central: ¿cómo es posible educar para obedecer? Y hablamos de educar sujetos libres, cuya libertad está en la obediencia y no en poder no obedecer. La respuesta fichteana es sin embargo muy compleja, pues Fichte no cree que el constreñimiento sea por sí solo suficiente. Ello se apoya en una posibilitad de división del yo finito, capaz de ser educado y de verse a sí mismo siendo educado y, por tanto, capaz, al mismo tiempo, de hacer un recorrido de las etapas anteriores del proceso educativo y dar un vistazo a las que aún le falta alcanzar. 0 , como Fichte también dice, un Yo capaz de mirar simultáneamente a los dos mundos: al mundo que ya existe y que no es más que la fijación provisional en un ser del devenir de la libertad, y al mundo que debe existir por la libertad (Fichte, 1845, p.447). Esta doble capacidad es fundamental. Ella permite a la conciencia que se educa mantener su unidad, le permite poder decir "Yo soy" en cada momento de su vida, sin que la unidad e identidad de este "Yo soy" dependa de las hipótesis metafísicas a las que, por ejemplo, el Cogito cartesiano se encontraba sujeto.

Ahora bien, para Fichte, en 1794-95, el Yo era, por un lado, posición de sí mismo $y$, por lo tanto, inconstruible, pero, por el otro, estaba siempre limitado 
por el no-Yo y, por consiguiente, en permanente construcción. Fichte retoma estas tesis suyas y las supera de dos modos diferentes: 1) primero, poniendo de relieve la existencia de una historia del proceso de superación de las limitaciones impuestas por el no-Yo, o, en otras palabras, una historia de la sedimentación de los actos de libertad; 2) segundo, admitiendo la necesidad de un proceso gracias al cual el Yo es educado para comprender la necesidad de realizar tales actos. Esta última idea tiene aspectos interesantes, pues está en la base de una concepción de la historia en la que, a cada época, le es reconocido el valor que le es propio. Fichte incluso afirma (Fichte, 1845, p.443) que una época nunca juzgará con imparcialidad a la que la precedió si simple y llanamente se pone en el lugar de ésta desde el punto de vista superior que le es propio.

Donde Maesschalck parece tener razón (pero para mí no la tiene, por lo menos no la tiene enteramente) es que hay aquí un problema muy semejante al que Husserl también encontró. Por un lado, el Yo husserliano parece recibir su unidad de los actos de reflexión, en la que reconoce sus actos pasados como actos suyos, aunque, por decirlo así, ya sin efecto en el momento en que reflexiona sobre ellos. (Estos actos perdieron, como diría Ortega, su carácter ejecutivo.) Por otro lado, el Yo necesita de la exploración del campo trascendental, o sea, de la reducción fenomenológica, para garantizar su unidad, o mejor, para superar la mera evidencia fáctica de esa unidad. Simplemente, este proceso se lleva a cabo en la primera persona y es llevado a cabo por el que Husserl designa como un “filósofo principiante", un anfänger Philosoph.

Es para mí muy claro en qué punto Maesschalck no tiene razón. La reducción fenomenológica permite explorar el campo trascendental, pero no lo abre. Este campo trascendental ya se encuentra abierto y está constituido por la totalidad de los hombres comprometidos en una historia común y que buscan un sentido final para ella. El anfänger Philosph no es un educador del género humano, aunque un anfänger Philosph pueda enseñar algo sobre los procesos llevados a cabo en la historia efectiva de los hombres en la medida en qué se transformó en su espectador. (Empleo otro concepto de Ortega.) Pero la tarea que la WL atribuye al Zwingherr es la tarea que Husserl atribuye a cada hombre: asumir la entera responsabilidad de sus actos.

Regreso, para finalizar, a la teoría fichteana de la división del Yo, aunque su posibilitad sea más supuesta que justificada en la Staatslehre. ¿Podría esta teoría de los dos Yoes ser de alguna ayuda en la comprensión de la naturaleza del Zwingherr?

1. ¿Es acaso el Zwingherr el phronimos del que habla Aristóteles? Esta sería una respuesta posible. Téngase en cuenta que, en relación con sus deliberaciones, Fichte dice: «la medida que se toma nunca es la mejor en general, sino la mejor para la época» (Fichte, 1845, p.444). Además, Fichte insiste (ídem, p.446) en que nadie se puede autoproclamar Zwingherr o Oberherr, dando por 
supuesto que sólo el reconocimiento público es capaz de instituir a alguien en tal función. ${ }^{4} \mathrm{Y}$ añade, un poco más adelante, que nadie se puede proclamar a sí mismo Zwingherr (ídem, p.446). La verdad debe hacerse vivible a través de él inmediatamente, sin que eso dependa de su albedrío (ídem, p.447).

2. Sin embargo, conviene no olvidar que el derecho, para Fichte, no es sino una aplicación de los principios de la Doctrina de la Ciencia a un dominio específico de la vida. Con estos principios definitivamente establecidos - que sólo pueden sufrir variaciones en el modo de su exposición - será siempre a la luz de ellos que la acción del Zwingherr deberá ser juzgada. En última instancia, por consiguiente, es a la luz de un cierto saber que se decidirá el valor de la acción del Zwingherr. Creo que esto es suficiente para distinguirlo del phronimos, pues la acción de éste (más que los principios de los que deriva) tiene siempre un papel determinante en el establecimiento de la regla por la que se juzgará lo que se hace.

3. El Zwingherr es quien tiene la capacidad de aplicar la ley eterna de la libertad para el momento concreto (ídem, p.444). Aquella ley dice: un ser libre no puede ser sometido a procesos que se deriven de las leyes causales de la naturaleza. Pero como Fichte sostiene que tal aplicación tiene la forma de un juicio infinito (ídem, íbidem), los problemas aumentan en vez de disminuir. Un juicio infinito - y aquí sigo lo que dice Kant al respecto - tiene en su base un juicio negativo. Así, al juzgar su época, el Zwingherr dirá, para empezar, que ella es una de las que aún no han alcanzado el ideal de la justicia. Será necesario - si estoy leyendo bien a Fichte - un segundo juicio que diga en qué época, de hecho, nos encontramos y cuál es el grado de coacción que le corresponde; es decir, que diga hasta qué punto los individuos aún no son libres, para ser coaccionados con vistas a la libertad.

Lo importante, por lo tanto, no es, en mi opinión (al contrario de lo que dijo Maesschalck), la atención a los actos fundadores de la comunidad - ya que nadie puede garantizar su validez permanente -, sino la atención a su posible inadecuación al presente, es decir, a la permanencia o no de su validez intersubjetiva. Las comunidades políticas tienen que refundarse periódicamente sobre la base de acuerdos siempre nuevos intersubjetivamente garantizados. Sin embargo, Fichte acusa a las filosofías como las de Locke o Rousseau de ser «ein Grübeln (...) auf gutes Glück» (“un cavilar... al buen tuntún") (Fichte, 1845, p.436). Para él, tales acuerdos tienen validez solo si se basan en principios posibles de deducir a priori. Tal deducción no se deriva de

\footnotetext{
4 Por esta razón (Bazzan, 2019, p.245), es legítimo hablar de la «torsión semántica» al que Fichte somete el término Zwingherr, que ya había caído en desuso en el vocabulario político y jurídico de la época, bajo su crítica por las ideas de la ilustración. Es decir, Fichte le da a la palabra un significado positivo que ya no tenía.
} 
los hechos históricos contingentes, aquellos que todos pueden conocer por sí mismos un poco como quien ha nacido con la capacidad de ver sabe cómo distinguir formas y colores. La deducción de tales principios comienza con una reflexión sobre lo que hizo posible tales hechos, es decir, la capacidad del hombre para autodeterminarse y transformar esa autodeterminación en un motivo para la acción. En el lenguaje de Fichte desde 1804, que Fichte recuerda en 1813, esta declaración significa: solo Dios es; fuera de él o de su vida, solo es su manifestación (ídem, p.431), la libertad humana según las leyes de la moral y del derecho.

Esto tiene como resultado, sin embargo, el lugar incierto pero inevitable del Zwingherr en la filosofía del derecho y del estado de Fichte. Él no es necesario para nada en una deducción a priori. Pero imaginemos a alguien capaz de ver formas y colores, pero y ciego a la visión con la que los ve. Tal persona sabe lo que existe, quizá lo conoce según leyes de la naturaleza, pero no sabe cómo surgió. Por esa razón es necesario enseñarle a ver de manera diferente. Es una situación similar a la que, según Fichte, requiere la presencia de un Zwingherr: su necesidad depende de ciertas condiciones históricas que impiden la completa actualización de la capacidad humana de autodeterminación.

\section{Referencias}

Bazzan, M. R. (2019). «El enigma del Zwingherr». In: Ferrer, D. (coord.), A Filosofia da História e da Cultura em Fichte. Coimbra: Imprensa da Universidade, pp.241257.

Druet, P.-P. (1974). La "politisation” de la métaphysique idéaliste: le cas de Fichte. Revue Philosophique de Louvain, 72(16), 678-712.

Fichte, J. G. (1845). Der Staatslehre. Sämtliche Werke (hrsg. von J. H. Fichte) Band IV. Berlin: Verlag von Veit und Comp., pp.369-600.

Fichte, J. G. (1985). Wissenchsftslehre 1804 / II. In: Gliwitzky, H. und Lauth, R. (hrsg.). J. G. Fichtes Gesamtausgabe Band II / 8. Stuttgart: Bad-Cannstatt.

Fichte, J. G. (1994). Wissenchsftslehre Nova Methodo. Hamburg: Felix Meiner.

Heine, H. (1834). De l'Allemagne depuis Luther. Revue des Deux Mondes, IV.

Husserl, E. (1959). Erste Philososphie. Zweiter Teil. Den Haag: Martinus Nijhoff.

Lauth, R. (1994). «L'action historique d'après la philosophie transcendantale de Fichte». In: Vernünftige Durchdringung der Wirklichkeit. Neuried: Ars Una, pp.373-406.

Maesschalck, M. (2006). «Introduction: Situation et enjeu de la Doctrine de l'État dans la dernière philosophie de Fichte». In : Fichte, J. G. La Doctrine de l'État. Paris: Vrin, pp.29-55. 
Piché, C. (2003). «La doctrine de l'état et la question de l'éducation». In: Goddard, J.-Ch. et Maesschalck, M. (ed.). Fichte. La Philosophie de la Maturité (18041814). Paris: Vrin, pp.159-174.

Renaut, A . \& Savidan, P. (2001). «As luzes críticas: Rousseau, Kant e Fichte». In : Renaut, A. História da Filosofia Política, 3. Lisboa: Instituto Piaget.

Recebido em: 29.03.2020

Aceito em: 19.07.2020

Esta obra está licenciada com uma Licença Creative Commons Atribuição-NãoComercial- Compartilhalgual 4.0 Internacional.

https://creativecommons.org/licenses/by-nc-sa/4.0/ 